\section{Scenes from the corridor}

\author{
Stuart Sutherland
}

Current Directions in Psychological Science. Editors S. Scarr and C. R. Gallistel. Cambridge University Press. 6/yr. \$125, £69 (institutional); \$63, £35 (personal). The International Journal for the Psychology of Religion. Editors L. B. Brown, Raiph W. Hood $\mathrm{Jr}$ and $\mathrm{H}$. Newton Malony. Lawrence Erlbaum. 4/yr. USA and Canada $\$ 125$, elsewhere $\$ 150$ (institutional); USA and Canada $\$ 35$, elsewhere $\$ 60$ (personal).

JusT as British industry suffers because managers seek short-term profits at the expense of larger long-term gains, so British (and indeed American) psychologists are obsessed by immediate productivity instead of thinking carefully about what projects are likely to be of most value in the long run. Many are so reduced to crossing the i's and dotting the t's of others' work that, on average, research papers are cited only about once after publication. Nowadays, it is admittedly extremely difficult for anyone to take an overall view, for the subject has become so fractionated that most workers know only of what is going on in their tiny corner of the field.

Current Directions in Psychological Science sets out to ameliorate such specialization by presenting short reviews of topics across the whole of psychology and aiming to "keep technical language to a minimum". Unfortunately the first page of the first issue belies the editors' intent, for on it R. J. Sternberg and T. I. Lubart write: "One of the less contextualised approaches is the structurally oriented psychometric approach". They proceed to give an account of creativity of such banality that it makes Arthur Koestler's outpourings on the topic seem like the work of Einstein. Their basic contention is that not all original ideas turn out to be of value. By calling this platitude "The Investment Theory", they invite others to take them seriously: the word "theory" when used by psychologists usually signifies that they have nothing to say.

In fact, this article is much the most disgraceful in the issues reviewed. Many of the other contributors give an accurate and clear account of the topics with which they deal and they demonstrate that at least some psychologists are advancing the subject. R. A. Rescorla shows that the learned associations made by animals are much more complex than anything dreamed of by Skinner or even Pavlov; $\mathrm{N}$. Graham gives a good review of the "binding problem" (how the separately detected features of an object are recombined to give a representation of the whole object); and $\mathrm{H}$. Gotlib provides a thoughtful discussion of different theories of the psychological origins of depression.

In the realm of personality, psychol- ogists are increasingly trying to account for individual differences in evolutionary terms. There is convincing evidence that sexual jealousy is more readily aroused in women by the emotional commitment of their partner to another woman than by mere sexual infidelity, whereas for men it is the partner's sexual act that fuels jealousy. The evolutionary interpretation is obvious.

Despite the catastrophic first article, this journal is for the most part clear, accurate and readable. Any psychologist who wants to know what goes on in the laboratory down the corridor should invest the very small sum required.

The International Journal for the Psychology of Religion represents yet a further specialization in psychology. Its main articles tend to be weak on theory: indeed some of them are mere hand waving. It is easy enough to derive reasons why people believe in God - after all,

\section{European snoozepaper}

\section{MaryA. Carskadon}

Journal of Sleep Research. Editor Jim Horne. Blackwell Scientific. 4/yr. USA and Canada \$151, Europe £92, elsewhere $\$ 101$.

PUBLISHED on behalf of the European Sleep Research Society and edited by the estimable Jim Horne of Loughborough University of Technology, Journal of Sleep Research has quickly established its niche in the scientific literature of this multidisciplinary field. Unlike the shortlived European periodical Waking and Sleeping of the 1970 s, JSR seems destined for an important continuing role. A distinguished panel of ten associate editors - all prominent members of the European Sleep Research Society - is complemented by an equally esteemed 52 member international editorial advisory board, although there could be more female representation on these panels.

$J S R$ maintains a distinctly international outlook and representation. In the first five issues, 55 per cent of articles emanated from European laboratories, 25 per cent from the United States and the rest someone other than Stephen Hawking must have invented the Universe, the promise of Heaven (though not available in all religions) is attractive and if you happen to be a freudian you can always posit the need for a father figure with far better qualities than your real father. But none of the authors tackles such outstanding questions as why people need religious ceremonies or rites of passage. For the curious, there are some interesting titbits. For example, an American study of 1,000 Roman Catholic priests found that 40 per cent were practising homosexuals, while a further 20 per cent were active heterosexuals.

Many of the articles are followed by critical comments: these are usually clear and informative and provide an understanding that cannot be gained from the main papers. The book reviews are excellent. Although the individual issues are rather slim, the price is reasonable and the journal should appeal to anyone interested in the serious study of religion or gossip about its adherents: it would have had the imprimatur of William James himself.

Meanwhile, someone somewhere is surely planning an even more esoteric publication, The Nationwide Journal of the Psychology of Psychologists.

Stuart Sutherland is in the Laboratory for Experimental Psychology, University of Sussex, Falmer, Brighton BN1 9QG, UK. from Canada, Israel and Asia. For members of the US sleep research community, $J S R$ provides a much needed immediacy of access to and a more intimate link with European colleagues. An important way in which the journal supports an international audience is through its reduced subscription fee to members of any "national sleep society".

Careful editorial screening has resulted in consistently high-quality science. For example, the second issue presented proceedings of a workshop on "concepts and models of sleep regulation". Published within a year of the workshop, the papers in this issue give an up-to-date overview of current theoretical perspectives. One paper unfortunately overlapped to a great extent with an original investigation that appeared in $J S R$ 's first issue - this is a hazard of guest editorship. $J S R$ has published two "symposia", the first on serotonin and the sleepwakefulness cycle, and the second on dream research methodology. The fivepaper serotonin symposium is excellent, but the limited scope of the dream symposium is disappointing. 